\title{
Syrianus on the Platonic Tradition of the Separate Existence of Numbers
}

MELINA G. MOUZALA / University of Patras /

Aristotle in books $\mathrm{M}$ and $\mathrm{N}$ of his Metaphysics, attacks the Form-numbers or the so called eidetic numbers and differentiates them from the monadic or unitary, i.e. the mathematical, numbers, namely the ordinary numbers which are addible to one another (sumblettoi) and composed of undifferentiated units (monades). Syrianus in his Commentary on Aristotle's Metaphysics defends the existence of eidetic numbers and justifies their necessity, by following a line of argument which puts forward the main characteristics of their divine and immaterial nature. In parallel he analyzes and explains the ontological status of mathematical numbers in a way which reveals that they have a kind of separate existence. This paper attempts to bring to the fore the most salient aspects of this argumentation and sets out to show how a neoplatonic Platonist such as Syrianus, understood the nature not only of the Form-numbers, but also of the mathematical numbers, through the transmission of the relevant Platonic tradition, especially with regard to Plato's unwritten doctrines. 


\section{Aristotle's classification of number in Metaphysics M6}

Aristotle in passage 1080 a 12-35 of his Metaphysics states that it would be well to turn once again to the investigation of the problems connected with numbers and more specifically with the theory that numbers are separate substances and primary causes of beings. ${ }^{1}$ He then proceeds with the assumption that if number is a kind of nature, and its essence is nothing else but that very thing, namely that it exists as a number, as some thinkers maintain, then it follows necessarily that indeed there must be something of number which is primary and something else which is next in succession (echomenon) and so on, each one being other and distinct in kind from anything else. In terms of the manner in which units are connected with each other within the number, Aristotle recognizes three disjunctive possibilities and makes the following threefold division: either i) the aforementioned otherness in kind applies directly to units, with the consequence that any unit is non-combinable (asumblètos ${ }^{2}$ ) with any other unit; or ii) all units are directly successive (euthus ephechsess) and any unit is combinable with any other unit, as they say is the case with mathematical number (for in mathematical number no unit is in any way different from another); ${ }^{3}$ or iii) some units are combinable and others not.

Aristotle clarifies within an extended bracket that in the last case if after one comes first two and then three and so on for the rest of the numbers, and the units in each number are combinable (those in the first two, for example, being combinable between themselves, and those in the first three among themselves, and so on with the other numbers), but the units in the original Two, in the Form of two (duas), are noncombinable with those in the original Three, in the Form of three (trias), and similarly with the other numbers in succession. In this last case after One, there is a distinct Two not including the first One, and a Three not including the Two, and the other numbers in a similar way. On the contrary in mathematical number after one comes two, namely another one added to the one before, and then three, namely another one added to those two before, and the remaining numbers likewise. In passage 1080 a 35-37 Aristotle states that one kind of number must be such as was first described (namely all the units non-combinable), another like the sort spoken of by mathematicians, and the third is that mentioned last. Furthermore in passage 1080 a $37-b 4$ he adds that these numbers must exist in separation from things, or not in separation, but in sensible things (in the sense that sensible things are composed of numbers which are present in them), - either some of them and not others, or all of them. ${ }^{4}$

\footnotetext{
1 In general outline I follow the translation by Dillon \& O’Meara (2006).

${ }^{2}$ Wilson (1904: 250) notes that when Aristotle attacks the Idea-numbers, he speaks of them as $\alpha \sigma v^{\prime} \beta \lambda \eta \tau o \iota$ $\dot{\alpha} \rho \iota \mu \rho i$, and it is exactly on their numerical side and not as mere Ideas that the epithet belongs to them and is relevant; most of his criticisms relate to their numerical aspect as Ideas of numbers solely.

3 In this last sentence I follow the translation by Annas (1976; repr. 1999).

${ }^{4}$ I follow the translation by Dillon \& O’Meara (2006) with slight changes.
} 
The main problem which emerges from passage 1080 a 15-37 is to decide if Aristotle presents the three kinds of number described in lines $18-35$ as divisions of the class established in lines 17-18. Ross ${ }^{5}$ notes that the sentence is irregular in structure; he points out that Aristotle begins (1.17) by stating what looks as if it were to be the first of a series of alternative hypotheses about the nature of numbers, but he proceeds to state three possible forms of this one hypothesis, differing in the view they take of the nature of units $(11.18,20,23)$ and recurs to numbers only in 1.35 . I agree with Tarán ${ }^{6}$ that there is a break in 1.18 , in the sentence which begins in 1.17 , where $\eta^{\prime} \tau \iota$ has been left without a comple-

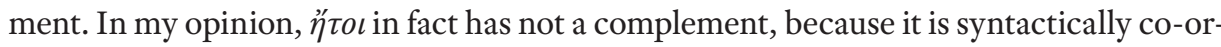

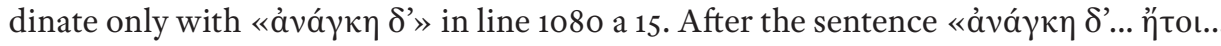

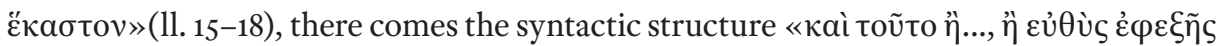

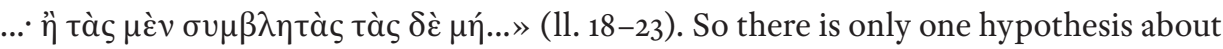
the nature of numbers and Ross is correct to state that Aristotle presents three possible forms of one hypothesis.

These three different kinds of number are recognized in terms of the different ways in which the units are related in each of them. If they are all divisions of the number referred to in passage 1080 a $17-18$, in which there is something prior and something posterior, and these ordered numerical elements are distinct in form, then all three kinds of number presented in 1080 a 18-35 are incomparable. If this is the case, the question is, how can Aristotle identify the second kind of numbers, namely incomparable numbers the units of which are all comparable, with mathematical numbers? Given that in 1081 a 5-7 he admits that if all the units are comparable or combinable and undifferentiated, then there is only one type of number, the mathematical, and it is obvious that for Aristotle, numbers of which all the units are comparable cannot be incomparable?

In my opinion, Ross's ${ }^{8}$ view is correct when he states that in 1080 a 20, Aristotle expresses the belief in incomparable numbers with units all comparable. But I agree with Tarán ${ }^{9}$ that Ross ${ }^{10}$ is wrong when he contends that Aristotle confuses incomparable numbers, the units of which are all comparable, with mathematical numbers. Nevertheless, I consider that Tarán ${ }^{11}$ is also wrong when he claims it improbable that Aristotle, having mentioned in 1080 a 18-20 the incomparable units, went then into a digression concerning the nature of the units as such, in which the question of the different kinds of numbers was lost sight of; he admits that such an interpretation would make sense in

\footnotetext{
5 Ross (1924: Vol. II, 426).

6 Tarán (1978: 89).

7 Cf. Arist. Metaph. 1081 a 17-21; see also Cherniss (1944: Vol. I., 514 ); Tarán (1978: 85).

8 Ross (1924:Vol. II, 426 ).

9 Tarán (1978: 85).

10 Ross (1924:Vol. II, 426).

11 Tarán (1978: 86).
} 
itself. ${ }^{12}$ It is worthwhile mentioning that Wilson ${ }^{13}$ has proposed an interpretation which makes possible such a digression. He states that in this ordered series described in passage 1080 a $17-18$, the numerical elements must be $\alpha \sigma v \mu \beta \lambda \eta \tau o$, but that there are two possible cases. Either the elements are the units, and then, if these have an order of prior and posterior, they must be all incomparable, or the elements are the numbers. If this is the case, then this series can only be formed by the third kind of numbers described by Aristotle in passage 1080 a $23-30$ and $33-35 .{ }^{14}$

In any case I agree with Tarán that Aristotle's classification of number is intended to attack the diverse Platonistic doctrines of number and "enables him to argue that if numbers actually exist apart from the sensibles, they must belong to one or another of the three categories of incomparable numbers he has set up, all of which he believes to be impossible" ${ }^{15}$. Moreover, although I completely agree with Tarán that the $\eta$ in passage 1080 a 35 is corrective, ${ }^{16} \mathrm{I}$ believe there is another possible explanation which sheds light on the logical sequence and ordering of the Aristotelian thoughts in passage 1080 a 17-37. The sense in which Aristotle uses the reference to the mathematical number in passages 1080 a 21 and 1080 a 36 is not the same. In the first passage he reserves the division which starts from 1080 a 18 and mentions the second kind of numbers which are incomparable, namely numbers which have all their units combinable. Nevertheless, he says that this is the kind of numbers they, i.e. some other Platonists, claim it is the mathematical number, and by that he means the other Platonists with the diverse doctrines about mathematical numbers. ${ }^{17}$ But when he returns to the discussion in passage 1080 a $35-37$, he does no more reserves the same classification which begins in lines $17-18$, because now he no longer refers to the second kind of incomparable numbers which he mentioned in passage 1080 a 21 . He refers only to the sort of number spoken of by the mathematicians, and this number according to Aristotle is an absolutely comparable number with all its units comparable. ${ }^{18}$

12 Aristotle could have connected the numbers which have an ordering relation and are distinct in form only with the first kind of number, referred to in passage 1080 a 18-19, in which the distinction in form applies directly to the units, since for him the next kind of numbers, namely those which have all the units comparable, are mathematical numbers, and these numbers are comparable, i.e. they are not distinct in form. Also, the third kind of number is not an instance in which the distinction in form applies directly to the units, because while the units of an Ideal number could not be combined with those of another, the combination of units is possible within the number itself.

13 Wilson (1904: 253).

${ }^{14}$ The disadvantage of Wilson's interpretation is that he does not include in his treatment all the three kinds of numbers which constitute divisions of the class established in 1080 a 17-18, since he omits the kind of number referred to in passage 1080 a $20-23$.

15 Tarán (1978: 87).

16 Tarán (1978: 89).

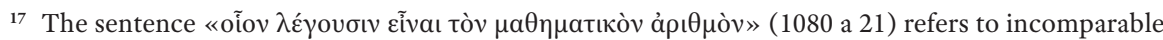
numbers with the units all being comparable. Tarán (1978: 86) is wrong when he says that it refers merely to the units' being all comparable, and not to incomparable numbers as such.

${ }^{18}$ Cf. Tarán (1978: 89-90), who offers a different justification. 


\section{Syrianus on the nature of Form-numbers or eidetic $^{19}$ numbers}

Syrianus ${ }^{20}$ notes that the first distinction made by Aristotle in passage 1080 a $17-18$ is defectively stated, but yet it is verily said for it necessarily follows that, if essential Number (Number itself) exists as a nature distinct from things that are subject to counting, either each following number differs from its predecessor in form or it does not so differ. He adds that Aristotle seems to pass over this alternative, "or it does not so differ". In my view it is obvious why Aristotle passes over this alternative, since if each number did not differ from its predecessor in form, then all numbers would be one united or unique number.

Furthermore, Syrianus states that the subsequent distinctions involving types of unit are all superfluous and disorientate or misdirect the enquiry; for if those men had postulated that separable numbers had their being in a quantity of units, it would have been proper to raise the question against them as to whether all the units are non-combinable or whether they are all indistinguishable or if some are indistinguishable and others distinguishable and non-combinable. ${ }^{21}$ But according to those who maintain that numbers are separable, he adds, ${ }^{22}$ the numbers concerned are partless and devoid of quantity and discerned as immanent within divine Forms, at least those of them that are separable from the cosmos. So according to Syrianus, it would not make sense to raise such questions, as if each separable number consists of a quantity of units.

Syrianus claims that from the distinctions Aristotle makes in passage 1080 a 17-23 and a 35-b 4, only the first and the last turn out to be substantial (pragmateiōdeis). He then states that he chooses from the first one the alternative that the different numbers are distinct in form, or rather that they are distinct Forms, for the pure and unsullied Forms are not separate from numbers. ${ }^{23}$ What we can infer from the words of Syrianus is that he completely identifies Forms with numbers and that different numbers are distinct Forms. These are partless and devoid of quantity, so it is quite meaningless for someone to speak of the units in the case of essential Number or eidetic number in the same way as we speak

19 According to Wilson (1904: 257) “it seems always assumed, perhaps without a sufficient examination of

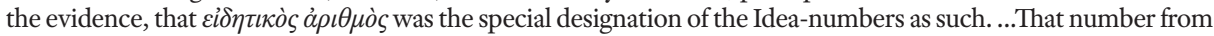

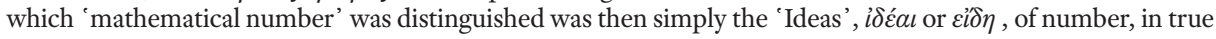
reference to number. If a collective expression for the $\varepsilon^{\prime} \delta \delta \tau \tilde{\omega} v \dot{\alpha} \rho \imath \theta \mu \tilde{\omega} v$, parallel to the collective $\mu \alpha \theta \eta \mu \alpha \tau \iota \kappa o ̀ \varsigma$

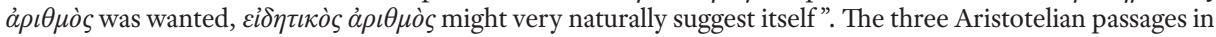

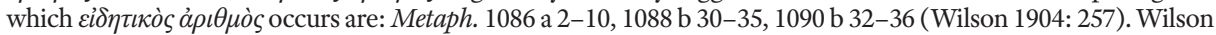

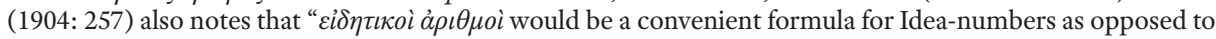
numbers in the ordinary sense, and may therefore have come to be the equivalent of Idea-numbers with them,

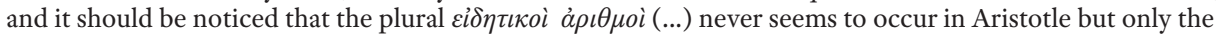

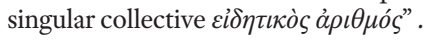

${ }^{20}$ All references to the text of Syrianus' Commentary on Aristotle's Metaphysics are to the page and line of the Berlin Academy Edition (CAG VI,1) and follow in general outline the translation by Dillon \& O’Meara (2006). See Syrian. 121, 11-14.

21 Syrian. 121, 14-21.

22 Syrian. 121, 21-24.

23 Syrian. 121, 27-31. 
of them in the case of mathematical number. He further clarifies in his comment on the same passage that if we are to say anything also about the difference or lack of difference between units, one must not on any account assign quantitative units to the essential numbers. ${ }^{24}$ But since those who maintain the existence of essential numbers speak of immaterial ${ }^{25}$ units, according to Syrianus we have to assert that all these units differ from one another by reason of otherness and are indistinguishable in virtue of sameness, and exhibit the combination of these characteristics, because both of these genera of Being pervade everything. ${ }^{26}$

In his comment on the Aristotelian passage 1082 a 32-b 1, Syrianus explains the relation between the eidetic number and the unit. He states again that the number of the Forms (ho tōn ideōn arithmos) is not unitary (monadikos), even if it is called a unit; it is a number as being a pure form (eidos), assimilating to itself those things that participate in it, but a unit as being the measure (metron) and the prior measure (prometron) of the forms which exist in the soul and in nature and in sense-objects. ${ }^{27}$ In my opinion, Syrianus seems to construe here the eidetic number, considered as a unit, as the paradigmatic cause of the rest of the Forms. Furthermore, in trying to answer Aristotle's objection expressed in passage 1082 a 32-b 1, he points out that in any case, according to those who support the existence of separate eidetic numbers, Forms are not composed of Forms, and all the arguments provided by Aristotle are more suitable to a comedian than to someone who investigates serious matters. ${ }^{28}$

\section{Syrianus's classification of number}

In passage 1080 b 11-14 Aristotle states that some hold that both kinds of number exist, that which involves priority and posteriority being identical with the Forms, i.e. the Form-number, and mathematical number being distinct from Forms and sensible things, but both kinds of number being separable from sensible things. ${ }^{29}$ According to Syrianus, it is obvious that in Aristotle's view, Plato belongs to this category. Moreover, Syrianus invokes Aristotle's commentator Alexander, who asserts this interpretation. Pseudo-Alexander verifies that Aristotle refers to Plato who postulated the existence of both kinds

24 Syrian. 121, 38-122, 3.

25 I do not think that it is necessary to accept Kroll's suggestion of aulous for MSS autous, but Dillon \& O’Meara (2006: 198, note 206) accept it.

26 Cf. Syrian. 122, 3-9; I paraphrase somehow.

27 Syrian. 134, 23-26.

28 Syrian. 134, 26-29.

29 Translation by Dillon \& D. O’ Meara (2006). 
of number, the Form-number or eidetic number and the mathematical number. ${ }^{30}$ Syrianus accepts that Plato says this, but not only this, adding that Plato postulated the existence of both kinds of number, i.e. of eidetic number, the Forms having an order within it, and also mathematical number, which is superior to physical number, but inferior to eidetic number, in the same way as Soul is superior to Nature, but secondary to Intellect. ${ }^{31}$ What we can infer from the words of Syrianus is that, according to his acceptance of the platonic tradition, he recognizes three kinds of number: the eidetic, the mathematical and the physical. The mathematical number is intermediate and corresponds to the Soul, which is also intermediate between Nature and Intellect. Consequently, the physical number corresponds to Nature and eidetic number to Intellect (Nous).

\section{Syrianus on the sorts of mathematical number}

We can deduce how Syrianus understands on the one hand mathematical number and on the other, the relation between mathematical and eidetic number, from his comment on passage 1080 b 21-23 of Aristotle's Metaphysics. In this passage Aristotle states: "Someone else says that the first kind of number, Form number, is the only kind, and some say that mathematical number is the same as this." ${ }^{22}$ Syrianus notes that may be this thinker viewed all kinds of number as being present in the eidetic number, those prior to it as it were proceeding into manifestation in it, while those subsequent to it are present in it as in their paradigmatic cause..$^{33}$

At this point it would be useful to consider what kind of number could be prior to the eidetic number, especially if prior here means superior. This could be a plausible meaning of prior, since we can understand that subsequent here means inferior and imitative. If eidetic number operates as a paradigmatic cause, then it is superior in comparison with those numbers present in it. Indeed, we can detect here a conversion of the typical platonic relation between eidos-paradeigma and its exemplifications or imitations or images. While the Platonic Form as paradeigma, considered on an onto--logical level is a common characteristic which is somehow present in all its examples inasmuch as these exist, and these exist since they participate in it, in this case the examples are present in the paradigmatic cause.

Kroll puts in a bracket the following sentence from Syrianus's comment on passage $1080 \mathrm{~b} 21-23$ : "this is the only sort of number and it is absolutely transcendent, and math-

30 Ps.-Alex. In Metaph. 745, 20-32. Dillon \& D. O’Meara (2006: 198, note 207) note that this allusion of Syrianus to Ps.-Alexander's commentary is significant for indicating the relation between them, and their common dependence on Alexander; see also Dillon \& O’Meara (2006: 8-11).

31 Syrian. 122, 11-16.

32 Translation by Annas (1976; repr. 1999).

33 Syrian. 123, 13-15. 
ematical number is the same as this". According to Syrianus, what Aristotle says here is that some wished to eliminate mathematical number in its general accepted sense, while they postulated the existence of only one class of number, the eidetic number, and the very same number was called by them mathematical number. Syrianus ${ }^{34}$ proceeds to an interpretation of this view, saying that mathematical number is of two sorts, the one unitary (monadikos) and the other substantial (ousiōdess). He adds that the substantial number is that by means of which the Demiurge is said to put in order the rational soul. He then explains that these thinkers did not think it reasonable to call "eidetic" the number which is acknowledged by the general public to be non-substantial, but that number which substantially exists in our souls and which by its innate power (autophuōs) generates unitary number, while not identifying it with eidetic number, they nevertheless did not disdain to call it "eidetic", in the same way as we are accustomed to call the intermediate reason-principles in the soul "forms".

Based on these words by Syrianus, we can infer that he recognizes two sorts of mathematical number, the unitary and the substantial, the latter being this which is substantially present in our souls and by means of which our rational soul has been ordered and structured by the Demiurge. Moreover, the latter is the efficient cause which by its innate power generates unitary number. In my opinion the reason why Syrianus mentions this division is to show that the thinkers which Aristotle refers to in passage 1080 b 21-23, do not in fact identify eidetic number with mathematical number, since they do not even identify it with the substantial mathematical number. They just call the latter "eidetic" number, but this is just a homonymy. This time Syrianus seems to draw a parallel not between mathematical number and the soul, but between substantial mathematical number and the intermediate reason-principles of the soul.

\section{Syrianus on the ontological status of mathematical number}

In terms of the structure and ontological status of the constituents of each mathematical number, Syrianus sets forth his views in his comment on the Aristotelian passage 1082 a 15-26. In my opinion, in this passage Aristotle poses two questions. In the first, he asks how is it possible that a number, e.g. two, can be a definite entity existing over and above the units of which it is constituted, namely over and above the two units in this example, and similarly with the other numbers? Aristotle offers two solutions to this problem; this can be either by participation of the one in the other, e.g. as "white man" exists besides "white" and "man", because it partakes in these concepts; or when the one is some differentia of the other, as "man" exists besides "animal" and "two-footed". ${ }^{35}$ The second question raised by Aristotle concerns the explanation of the unity of the units

\footnotetext{
34 Syrian. 123, 19-25.

35 Translation by Dillon \& O’Meara (2006).
} 
within each number. He states that some things are one by contact, others by mixture, and others by position, but none of these alternatives can possibly apply to the units of which two and three consist. ${ }^{36}$

Regarding the first question raised by Aristotle, Annas notes that the Aristotelian argument here appears to suggest that, "The Platonists just present us with a collection of units, and a collection is not an entity over and above its members". Moreover, she points out that this is a simply anti-platonist point, and that Aristotle adds examples to show that it is not limited to units. ${ }^{37}$ Syrianus demonstrates in his Commentary that the argument implied within the first Aristotelian question (1082 a 15-20) intends to dispute the existence of separable numbers, but divine numbers are not an easy target. According to Syrianus, "the objection is not relevant to divine numbers at all; for these are not unitary in such a way that we may ask in their case what each of them is over and above the units composing them" (transl. Dillon \& O’Meara). ${ }^{8}$

Regarding the second question posed in the Aristotelian text (1082 a 20-26), Annas notes that the original question is, "How can a number like two be a unity, on this option? It fails all the conditions Aristotle accepts for a thing's being a genuine unity". ${ }^{39}$ It is obvious that by using the words, "all the conditions Aristotle accepts", Annas means contact, mixture and position, i.e. the conditions Aristotle mentions in this passage. But are these indeed all the conditions Aristotle accepts for a thing to be a genuine unity? J. Annas states that the aforementioned question seems to be a development of a single elliptical sentence at 992a 1-2: "why is a number, when taken all together, one?". ${ }^{\circ 0}$ In my opinion, this problem is raised twice in a more serious and decisive way in book $\mathrm{H}$ of Aristotle's Metaphysics, where it is associated with the more general ontological problem of the unity of both substance and definition.

In the passages $\mathrm{H}_{3}, 1044$ a 2-6 and $\mathrm{H} 6,1045$ a 7-8, Aristotle poses the question of the unity of number in connection with the problem of the unity of definition. In the first passage he states that, “... number must be something in virtue of which it is a unity, though people cannot now say what it is that makes it so, if indeed it is. (For either it is not, but is like a heap, or it is, and then it should be explained what it is that makes it one out of many)" ${ }^{41}$ In the second passage and generally in chapter H6, Aristotle returns to this problem in order to focus on the matter of the unity of definition. ${ }^{42}$ In this chapter he

\footnotetext{
${ }^{36}$ Aristotle adds that just as two men do not constitute any one thing distinct from both of them, so it must be with units too; the fact of their being indivisible will make no difference; points are indivisible also, but still two of them do not make up anything over and above the two; translation by Dillon \& O’Meara (2006).

37 Annas (1976; repr. 1999: 171-172).

38 Syrian. 132, 4-6.

39 Annas (1976; repr. 1999: 171-172).

40 Annas (1976; repr. 1999:172).

41 Translation by Bostock (1994).

42 As Bostock (1994: 279) puts it: "Aristotle opens his discussion with the general principle that whenever a thing has parts, but is not to be identified with the sum of those parts, then there is always a cause of its unity";
} 
elaborates on the theory that a definition is a unity because the definiendum is a unity. ${ }^{43}$ Furthermore, he offers a solution to the problem of the unity of definition by using as his strongest argument the unity of matter and form. In fact, as Bostock puts it, he comes to see the unity of matter and form as somehow providing a definite solution to the much wider problem of the unity of predication. ${ }^{44}$ According to the exegesis of pseudo-Alexander, matter and form both have an innate capacity to be one. ${ }^{45}$

Returning to Syrianus, we see that he considers the above mentioned objections irrelevant to the divine numbers; not only the first Aristotelian objection, that expressed in his first question (1082 a 15-20), but also the second, included in passage 1082 a 20-26. So he chooses to answer this second objection, which is related to the cause of the unity of number, with respect to mathematical number because he believes it is more properly directed against mathematical number. ${ }^{46}$ This means that he interprets the unity of each divine number as indisputable, so refusing even to discuss the matter. But the most striking aspect is that Syrianus attempts to answer the question as to the unity of mathematical number, by following a hylomorphic approach. This means that he chooses to oppose the Aristotelian viewpoint by using its own weapons. If the mathematical number is constituted of matter and form, then it can be a unity, because matter and form have an innate capacity to be one.

Syrianus addresses Aristotle and states: "since we see that in each thing, according to you also, there is one element that is like matter and another like form, so also in the Five, the five units and in general the quantitative element and the substratum come to numbers from the Dyad, whereas the form, as represented by the Five, comes from the Monad". ${ }^{47}$ Syrianus continues by saying that every Form is itself a monad and defines the underlying quantity, and so the Five is itself a sort of monad, because it proceeds from the ruling Monad, and it both gives form to the quantity subject to it, which was hitherto formless, and binds it together to its own form. ${ }^{48}$

\section{1. Syrianus on the principles of mathematical number}

Syrianus argues that there are two principles of mathematical number existing in our souls, from which the whole of the mathematical number is born. The first principle is the monad, embracing within itself all the Forms of the numbers and being analogous to

\footnotetext{
a heap (sōros) is given as a typical instance of something that is just the sum of its parts.

43 Cf. Bostock (1994: 279)

44 Bostock (1994: 288-289).

45 Ps.-Alex. In Metaph. 521, 8; see also Mouzala (2008: 87).

46 Syrian. 132, 6-7.

47 Syrian. 132, 7-10.

48 Syrian. 132, 11-14.
} 
the Monad in the intelligible realm. The second principle is the dyad, which constitutes a sort of potency that is generative and formless and of infinite power. Because of these characteristics this second principle assumes the role of an image of the inexhaustible and intelligible Dyad and it is for this reason that we call it the "indefinite dyad". ${ }^{49}$ The next passage from Syrianus shows that the two principles operate in a complementary way during the process of generation, because the dyad runs over all things and the monad constantly articulates and structures and adorns unceasingly with forms and puts in order whatever proceeds from the dyad, since this is always just an indefinite quantity..$^{50}$

We see here that there is a strong affinity between this theory of principles of numbers, in its general outline, and what Aristotle testifies about the platonic theory of principles in his Metaphysics passage 987 b 18-27. In this passage it is said that, since according to Plato, the Forms were the causes of all other things, he thought their elements were the elements of all things. Aristotle adds that according to Plato, the numbers are derived from the Great and the Small by participation in the One, and that it is peculiar to him to posit a dyad and construct the infinite out of great and small, instead of treating the infinite as one, as the Pythagoreans did. ${ }^{51}$

Alexander in his Commentary explains that Plato's view was that the Forms are the principles of the other things, and since the Ideas are numbers, the principles of number are principles of the Ideas. Moreover, Plato said that the principles of number are the unit and the dyad and that the One is principle of all things. ${ }^{52}$ Given that there are in numbers both the One and that which is apart from the One, and the latter is represented by the many and the few, the dyad is the first thing apart from the One, containing within itself both manyness and fewness; manyness and fewness are reduced to the double and the half, and these are in the dyad. ${ }^{53}$ Again, thinking he was proving that the equal and the unequal are the principles of all things, according to Alexander, Plato assigned the equal to the unit and the unequal to excess and defect; for inequality involves two things, a great and a small, which are respectively excessive and defective. Alexander states that it is for this reason that Plato also called it the "indefinite" (aoristos) dyad, because neither of the two, neither that which exceeds nor that which is exceeded, is, of itself, limited (hörismenon), but indefinite and unlimited. Alexander adds that when the indefinite dyad has been limited by the One, it becomes the numerical dyad. This kind of dyad is one in

49 Syrian. 132, 14-20.

50 Syrian. 132, 20-23.

51 I follow the translation by Ross (The Internet Classics Archive), in general outline.

52 Alex. In Metaph. 56, 3-8. All references to the text of Alexander's Commentary on Aristotle's Metaphysics are to the page and line of the Berlin Academy Edition (CAG I) and follow in general outline the translation by Dooley (1989).

53 Alex. In Metaph. 56, 8-13. 
form; ${ }^{54}$ and the dyad is certainly the first number and its elements are the One and the great and the small..$^{55}$

At this point it would be useful to consider the differences between Alexander's and Syrianus's explanation of the principles of numbers. Alexander ${ }^{56}$ points out that the principles of numbers are the monad and the indefinite dyad, and that the latter after being limited by the One becomes the dyad in the numbers, and this is the first number and its principles and elements are the One and the great and the small. On the other hand, Syrianus asserts that the principles of mathematical numbers are the monad, which embraces within itself all the Forms of the numbers and is analogous to the Monad in the realm of intelligibles, and the dyad which is an image of the inexhaustible and intelligible Dyad. This dyad is also called "indefinite", but this is just a homonymy. So it seems that Syrianus duplicates the principles with regard to the mathematical numbers, since the principles of mathematical numbers are only "images" of-or analogous to-the real principles of numbers. ${ }^{57}$ Apart from this, the characteristics which Syrianus ascribes to his "indefinite dyad" are different to those which Alexander chooses to focus on and analyze in order to describe the original indefinite dyad, that which Syrianus refers to as "the inexhaustible and intelligible Dyad”.

On the one hand, Alexander is more interested in justifying and explaining why the dyad as a principle is called "indefinite". For this reason he focuses on its structure and the special characteristics of its elements; specifically, on the characteristics of that which exceeds and that which is exceeded, namely on the indefinite and unlimited character of excess and defect, since these are the two elements of the indefinite dyad. On the other hand, Syrianus seems to select and highlight characteristics which are more compatible with the role and ontological character of the Aristotelian matter ( $h u l \bar{e})$, since his own "indefinite dyad" is described as a potency that is formless and of infinite power. ${ }^{8}$ Despite this, the fact that it is characterized as a generative potency makes it a more active and efficient principle than the Aristotelian matter (hulē).

54 Alex. In Metaph. 56, 13-21.

55 Alex. In Metaph. 56, 21-22; 56, 31-33.

56 Alex. In Metaph. 56, 7-8; 22-33.

57 Sheppard (1982: 2-4) points out that Syrianus expounds his view of the monad and the dyad at a number of places in the "Metaphysics" Commentary. The fullest exposition of his view appears at 112. $14 \mathrm{ff}$., but there are also important expositions at 129. 4ff.; 131.34ff.; 160, 18-19; 169. 2ff. In the first passage Syrianus states that the two principles, here called a monad and the dyad "infinite in power", come immediately after the transcendent One and they are causes of the things as a whole; they reappear at every level of beings. Sheppard (1982: 2-3) notes that Syrianus distinguishes between this transcendent monad and dyad on the one hand, and on the other hand the aủtopovàs and the aủtodvàs which appear in the realm of Forms; she further pinpoints that it is not always clear when Syrianus is talking about the monad and the dyad only in relation to numbers, and when he is talking about the supreme cosmic principles (1982: 4). She adds that 'second' and 'third' versions of the monad and the dyad, as principles of the universe, would be the lower causes analogous to these principles (1982: 4).

58 Cf. Arist. Phys. 192 a 25-34; 207 a 25-26; Metaph. 1036 a 8-9; 1037 a 27. 
Moreover, Alexander's explanation emphasizes the relationship between the indefinite dyad and its elements which are basically mathematical concepts. These include the many and the few, in turn reduced to the double and the half, to the unequal, to the great and the small, and finally to that which exceeds and that which is exceeded, i.e. to excess and defect. Alexander also stresses in his explanation the contrariety between the indefinite dyad and the One, when referring to their primary opposing characteristics. As he points out, according to Plato the One is indivisible but the dyad divided, and the unit is associated with the equal but excess and defect, the elements of the dyad, are associated with the unequal. Alexander's explanation reminds us of what Aristotle testifies in his Physics about the old traditional view of the philosophers, that the One and excess and defect are principles of all things..$^{59}$

Conversely, Syrianus emphasizes the cooperation or synergy between the monad and the indefinite dyad during the process of generation of numbers. Moreover, his terminology reminds us of the way in which Aristotle describes matter and form, i.e. as the two constituents of every substance which are complementary to one another. ${ }^{60} \mathrm{He}$ also focuses on the analysis of the relationship between the principles of mathematical numbers and the original principles, i.e. the Monad and the Indefinite Dyad which are principles in the realm of intelligibles; for the principles of mathematical numbers exist in our souls, so they are distinguished from the latter.

\section{2. Syrianus on the structure of mathematical number}

Syrianus clarifies that number Five is a unity, but the unity of Five is not due to the conditions Aristotle accepts for the genuine unity of a thing in the passage 1082 a 17-21. This is because Five is neither constituted from substance and accident, nor yet from genus and differentia, nor by five units being in contact with each other, nor by being mixed together, nor by submitting to being placed in certain position. ${ }^{61}$ Furthermore, from what Syrianus states in passage 132, 33-34, we can infer that he makes a distinction between numbers and countable objects (arithmèta). In the case of countable objects Syrianus accepts that there is nothing over and above the individual objects, although he points

59 Alex. In Metaph. 56, 12-18; cf. Arist. Phys. 189 b 11-16.

60 Syrianus refers to the "indefinite quantity" $(132,21)$ and "unstructured quantity" $(132,26)$ which is articulated and structured and formed $(132,22)$; cf. the word $\alpha \rho \rho \dot{v} \theta \mu \sigma \tau o v(132,26)$ of Syrianus with the same word used in Arist. Phys. 193a11. See also Phys. 192a 13-25, where Aristotle describes the relation between matter and form as the relation between feminine and masculine; within this philosophical frame hule (matter) has a strong desire for eidos (form).

61 Syrian. 132, 29-33. 
out that according to Plato, countable objects receive the different numbers by virtue of participation in some Form, and he invokes passage 101c of the Phaedo at this point. ${ }^{62}$

Syrianus asserts that it is not because numbers are composed of indivisible units that they have something other than those units, but because there is something in them analogous respectively to matter and to form. He then attempts to explain the structure and the elements of each mathematical number using as an example number seven. According to Syrianus, when we add three to four and make seven, we express what we are doing in these terms, but our statement is actually not true. The mathematical number seven is constituted of the Form of Seven (heptas) and a substratum; the units when joined together with the other units make up the substratum of the number seven, so number seven is made up of this quantity of units and the Form of Seven (heptas). ${ }^{63}$ According to Syrianus, even though in mathematical number seven the seven units never exist independently of the Form of Seven, yet the seven should be described by the science that sets out these things to be something composite, containing one element analogous to Matter and substratum, another to Form and structure. ${ }^{64}$

But if we accept that there is a substratum and a Form applied to it, this raises the following question concerning the efficient cause. What is it, then, that applies the Form of Seven to the units? Syrianus answers this question by drawing a parallel between the soul of the carpenter ( $p s u c h \bar{e} t e k t o n i k \bar{e}$ ) and the soul of the mathematician ( $p s u c h \bar{e}$ arithmètikē). What is it that applies the Form of Bed to such and such a combination of pieces of wood? The soul of the mathematician, by possessing within itself the originative Monad, imposes form upon, and generates, all numbers, as the soul of the carpenter, in virtue of possessing the appropriate art, imposes form on bits of wood for the making of a bed. But there is a difference inasmuch as there is a difference between the arts. The art of carpentry does not exist in us by nature and needs the handicraft, since it is concerned with sense-perceptible matter, while the art of arithmetic is both naturally inherent in us (which is why it is possessed by all), and is concerned with a kind of matter which is the object of discursive intellect (hule dianoèt $\bar{e}^{-65}$ ). It is for this reason that it is able to shape it both easily and timelessly. ${ }^{66}$

Furthermore, Syrianus draws a distinction between all the units underlying mathematical numbers and the one which is principle to all of them, i.e. the Monad. According to this distinction all the units underlying numbers are undifferentiated, apart from

${ }^{62}$ Syrian. 132, 33-38. In this passage of the Phaedo Socrates assures his interlocutors that the only, i.e. the true, cause of becoming two is participation in the dyad.

63 Syrian. 132, 38-133, 7.

64 Syrian. 133, 26-29.

${ }^{65}$ Mueller (2000: 78) points out that the phrase 'dianoetic matter' is an hapax; cf. Syrian. 186, 30-32, where the commentator states that to the mathematical numbers we grant, if not such matter as is present in the natural world, yet at least mathematical matter (hule mathematikē), as the quantitative element which underlies them (tèn hupobeblèmenèn posotèta).

66 Syrian. 133, 9-15. 
that one, i.e. the Monad, which is the first principle and fount and mother of all. Exactly because all the Forms actually proceed from it into all numbers, it is far from needing anything to impose form on it. ${ }^{67}$ Syrianus traces two kinds of homonymy; the many units in the mathematical number are homonymous with the Monad, but also the definite dyad among the mathematical numbers is homonymous with the Indefinite Dyad. The Indefinite Dyad is the first principle of all number, but particularly of the even, while the definite dyad is a principle in a different way, not as being generative, but rather as we say that the first part of any thing is its principle as an element of it. ${ }^{68}$

In passage 1082 b 1-5 Aristotle states that in general, making units different in any way is absurd and strained (plasmatōdes), and he adds that by "plasmatōdes" means "forced in order to fit one's assumptions" ${ }^{69}$ He then points out that we can see that one unit differs from another neither in quantity nor in quality. Syrianus praises Aristotle, noting that this is well said with regard to the units which make up any (mathematical) number; for neither will the units differ in quantity, since all are minimal, nor in quality, for they are formless..$^{70}$ Aristotle then explains in passage $1082 \mathrm{~b} 5-11$, that a number must be either equal or unequal and that this distinction applies to all numbers, but especially to unitary number. Syrianus also praises Aristotle for this statement, saying that equality and inequality runs through all number, whether natural or supernatural or mathematical. But according to Syrianus, what is most important in Aristotle's statement is the admission and clear confirmation of the doctrine of the ancients, that not all numbers are unitary. Syrianus states that from this one can infer that nothing has been demonstrated to us about non-unitary numbers, since Aristotle has based all of his arguments on the assumption of units. ${ }^{71}$

Especially important to us is Syrianus's comment on the Aristotelian passage 1082 b 7-11, from which we can gain further insight as to his view on the relationship between the sets of the units which make up any mathematical number and the mathematical number as a whole. In this passage Aristotle defines the equal number and then states that things which are equal and entirely undifferentiated, we assume to be identical in the sphere of number, otherwise not even the twos in the original Ten will be undifferentiated, though they are equal. ${ }^{72}$ The question Aristotle raises at the end of this passage implies that if one maintains that they are undifferentiated, one has to provide an adequate reason in defense of this view. Annas suggests that in this argument there is a rather dubious slide from talk of numbers being equal to talk of what is equal in numbers. According to her interpretation, Aristotle's aim is to show that the difference

\footnotetext{
67 Syrian. 134, 29-33.

68 Syrian. 134, 33-135, 3.

69 I follow the Annas' translation (1976; repr. 1999).

70 Syrian. 135, 5-6.

71 Syrian. 135, 9-14.

72 Partly I follow the translation by Dillon \& O’Meara (2006) and partly Annas' (1976; repr.1999).
} 
between numbers cannot be a difference in the units, and tries to do so by showing that sameness of number entails sameness of units in the number. ${ }^{73}$

Nevertheless, Syrianus again praises Aristotle for his remarks concerning the multiplicity of units and for the assumption that not only are units undifferentiated, but also numbers that are equal to one another. He then answers Aristotle's question by providing the reason why not only are units undifferentiated, but also sets of units within each mathematical number. For example, three would be just one thing, even though it is taken many times in making up thirty, for what are equal within the realm of numbers are identical. ${ }^{74} \mathrm{He}$ then justifies why the dyads in the decad are also undifferentiated. They are undifferentiated not just because their units are undifferentiated, though this is also the case, but because their Form is one. Moreover, its unity is due not to having given itself to undifferentiated subjects, for it makes only one single dyad numerically, but to having proceeded from the original Monad and remaining itself purely one. ${ }^{75}$ So the cause of the lack of difference among the dyads within the decad is their Form which is one and the same for every set of two units.

Syrianus stresses that even if we ourselves granted that the decad was made up of five dyads, exactly as it has ten units, it would have been necessary to agree that, while there are many dyads numerically, all these are one in form. He further clarifies two things about the decad: a) the dyads do not make up the decad because they have been put together, since the Forms of numbers are simple and proceed from the Monad, and this is also the case with the decad; b) the units underlying the dyad, being extended further, do not become the substratum of the decad, which proceeds from its own originating principle and brings about number Ten after being combined with the substratum. For these two aforementioned reasons, according to Syrianus, we are not compelled to postulate numerically many dyads, in order not to convert numbers into countables (arithmèta). ${ }^{76}$

Syrianus points out that if there were many dyads, as Aristotle himself asserts, and many triads and many decads, then generally each of the unitary numbers would be many and infinite, and it would have also been necessary that mathematical number as a whole would not be one, but there would be infinitely many mathematical numbers. ${ }^{77}$ Syrianus strongly objects to this hypothesis, assuming that since mathematical number is universal, there seems to be just one. Consequently and each particular mathematical number must be one, in order that the total composed out of these may also remain one. ${ }^{78}$ Moreover, he notes that if someone claims that the total mathematical number exists in infinite multiplicity like the individual things that are one only in form (ta homoeide tōn kath' hekas-

\footnotetext{
73 Annas (1976; repr.1999: 172).

${ }^{74}$ Syrian. 135, 16-19.

75 Syrian. 135, 19-23.

76 Syrian. 135, 23-32.

77 Syrian. 135, 32-136, 3.

${ }^{78}$ Syrian. 136, 3-6.
} 
$t a$ ), we will refer back once again to the single Form which mathematics examines; and we will find, according to Syrianus, one single Form of the total mathematical number, embracing a single Dyad and a single Triad and not many of them, in order that the total number will not become once again multiple, and this proceed to infinity.79

Furthermore, Syrianus explains that when we investigate the way in which the dyad relates to the decad, we need to avoid understanding this relationship as if the decad had been divided into or composed of five dyads. Instead of saying that we will divide the decad into five dyads, we should rather say that we take five times the subject-matter of the dyad. Nor do we compose the decad of five dyads, in order not to present its Form as being composite, something we cannot even see happening within sensible forms in the realm of Nature. At the end of his comment on passage $1082 \mathrm{~b} 7-10$, Syrianus states that in general we do not say that number is multiple as being divided in accordance with its subject-matter, but rather that each number exists so as to have manifold instantiations, if we intend to preserve it in its pure status as a number and not make it a countable. ${ }^{80}$

\section{Syrianus's presentation of the mathematical number}

The crucial problem that emerges from Syrianus's presentation of the mathematical number is the point Mueller stresses. If the dyad is a form and it is realized five times within the example of the decad, then "it seems that we can no longer speak of mathematical numbers differing 'from forms in that there are many alike, while the form itself is in each case unique:' the mathematical numbers are themselves unique" ${ }^{81}$ According to Mueller "Syrianus places so much emphasis on numerical forms or logoi that he ends up identifying mathematical number with substantial number, leaving monadic number with no significant independent role." ${ }^{2}$

Lernould also notes that the insertion of a formal element, of a formal cause, in the monadic number, in a sense brings about the conversion of this number into an eidetic number. This would tend to diminish the distinction between the monadic and the eidetic number, inasmuch as one can say that the seven of the mathematician, considered as form, as heptad, exists separately from the monads which constitute part of its composition. ${ }^{83}$ Another objection is that the analysis of number five into matter and form seems to mean that we isolate five units as matter of the number, and this would certainly imply that number five exists already before its form comes to be applied to the units of the very same number. This analytical process could lead to a regression to infinity, if we assume

\footnotetext{
79 Syrian. 136, 6-11.

80 Syrian. 136, 11-17.

${ }^{81}$ Mueller (2000: 79).

82 Mueller (2000: 75).

${ }^{83}$ Lernould (2009: 152).
} 
that the matter which constitutes the five units is also composed of matter and form, i.e. of the heptad, and so on to infinity. ${ }^{84}$ A relevant objection is that the five units which constitute the matter of the mathematical number are not supposed to be a completely indeterminate matter, a matter which is appropriate for receiving any kind of form and becoming any number; according to this reasoning, that matter must be considered as a kind of draft, as a foreshadow of number five, so again we have to explain a kind of pre-existence of number five before number five comes to existence, i.e. before the matter of this number receives the form of pentad..$^{85}$

In my opinion, all of the answers to the above questions and objections are implied within the very explanation of the nature of mathematical number given by Syrianus. He stresses that the majority of people have been fooled into thinking that seven is nothing else besides the relevant number of units. ${ }^{86}$ Put differently, Syrianus argues that the majority of people wrongly believe that the multiplicity of units, i.e. the relevant number of units, is a sufficient explanatory cause of the existence and constitution of numbers. Furthermore, we can add that most people think that mathematical operations suffice to explain the causes of generation and existence of numbers and this is what Socrates blames for their failure to understand the real causes of numbers and all things in passage $96 \mathrm{e}-97 \mathrm{c}$ of the Phaedo. Also, Syrianus's view is that the error of the majority of people is due to the common but unwarranted assumption that mathematical operations can be considered as the only, i.e. the true, explanatory causes of the existence of numbers. ${ }^{87}$

Burnyeat points out that although the question, "what are the oúoía and principles of the things that are?" is not a question in the philosophy of mathematics, the Platonists' answers invoke mathematical themes when they are asked for the most general principles of explanation..$^{88}$ According to the Platonic view, the causes of generation and existence of numbers lead us to the causes of Forms, i.e. to the causes of all other things, since Forms are the causes of all other things and pure Forms are not separate from numbers. ${ }^{89}$ Forms can be conceived of as numbers inasmuch as they operate as causes, which in a sense means that we can count them as measures for their effects, since they endow things that participate in them with order, beauty and unity. ${ }^{90}$

In my view it is clear that Syrianus tries to answer the Aristotelian question about the causes of the separate existence of numbers, by providing also a solution to the problem

${ }^{84}$ Lernould (2009: 148)

85 Lernould (2009: 148).

86 Syrian. 133, 16-17.

${ }^{87}$ Cf. Mueller-Jourdan (2009: 166-167).

${ }^{88}$ See Burnyeat (1987: 216); Burnyeat refers to the passages $\Lambda$ 1, 1069 a 33-36 and M 9, 1086 a $21 \mathrm{ff}$; moreover, he notes that the Platonists' answers, not the question, are responsible for MN's focussing on mathematical themes.

89 See again Syrian. 121, 30-31.

90 O’Meara (1989:135) points out that Syrianus "understands the relation between Forms and numbers in a 'Pythagorean' way: ideal numbers represent a Pythagorean way of speaking of Forms”, since by referring to 
of the unity of number. Both these questions have an ontological character. He chooses to answer Aristotle's question regarding the justification of the unity of number by adopting a hylomorphic approach of mathematical number, namely by using the very same philosophical and methodological weapons of Aristotle. Syrianus proceeds to the analysis of the mathematical number into matter and form, and this solution permits him to apply the Platonic thesis of the separate existence of numbers to the mathematical or monadic numbers themselves. ${ }^{91}$ However, we must take into consideration that he manages to do this only by combining a basic Aristotelian ontological doctrine, and what is more, a doctrine which concerns sensible substances, with the Platonic tradition of the separate existence of numbers, and this procedure entails to a certain degree the Platonic modification of the Aristotelian doctrine of hylomorphism, so as to conform to the Platonic Ontology.

Within this frame of reference, Syrianus clarifies that the units of mathematical number are only its substratum or matter, which can never exist independently of the form of the number, ${ }^{92}$ and that all mathematical operations, addition, subtraction, division and multiplication, apply only to the substratum, i.e. to the units. ${ }^{93}$ The cause of being of each mathematical number is its form, which coincides and is identified with its formal cause. Number seven owes its existence to the Form of Seven (heptas), since the seven units are not yet number seven, before the application of the Form of Seven to them. It is crucial for us to understand that according to Syrianus it is the science of mathematics which describes each mathematical number as something composite and that the constituents of mathematical number are just analogous respectively to matter and form. ${ }^{94}$ From this analogy emerges the cause of the unity of mathematical number; the unity of mathematical number is analogous to the unity of every composite in the realm of nature, since matter and form both have an innate power to be one (autophuoss $\left.h e n^{95}\right)$. So, from these remarks we can infer that the analysis of the mathematical number into matter and form is primarily presented by Syrianus as a knowledge-theoretic necessity, or an epistemological postulatum. This reflects the need of mathematics to analyze number into its constituent elements in order to interpret and understand its ontological status, since its composition and the way in which its elements are related to one another determine its ontological structure and value. This thesis of Syrianus reminds us also of

Forms as numbers the Pythagoreans expressed through mathematical analogy significant ontological features of Forms; see Syrian. 103, 15-104, 2; 134, 22-26; 137, 7-9.

${ }^{91}$ Cf. Lernould (2009: 151).

92 Syrian. 133, 26-27.

93 Syrian. 133, 4-7; 134, 14-19; 135, 25-28; 136, 11-15; 136, 27-36.

94 Syrian. 133, 3-4; 133, 27-29; see also Lernould (2009: 149, note 47).

95 See above note 45 . 
the method Aristotle proposes and uses for the study of natural things within the framework of the science of Nature in his Physics. ${ }^{96}$

Syrianus points out in his comment regarding passage $1084 \mathrm{~b} \mathrm{20-23,} \mathrm{that} \mathrm{taken} \mathrm{by}$ itself, each of the units of a mathematical number exists potentially and not in actuality, both in truth and according to the doctrine of the ancients. ${ }^{97}$ Moreover, he adds that if number is not a heap (sōros) of units, but each one, while being made up of a definite number of underlying units, is constituted in accordance with the Form proper to itself, the unit within a number would be nothing in actuality, before it was given order by the Form proper to it. ${ }^{98}$ Here again we can trace the influence of Aristotelian thought on Syrianus's argumentation, since it is Aristotle who claims in passage 1039 a 3-14 of his Metaphysics, that it is impossible for a substance to be composed of substances present in it in actuality. For what is in actuality two things cannot also be in actuality one thing, though a thing may be one and at the same time potentially two. Therefore, if a substance is one thing, it cannot be composed of substances present in it. ${ }^{99}$ Aristotle in the same passage refers to number as a representative instance of this ontological situation, saying that if number is, as some suggest, a synthesis or combination of units, either the number two is not one, or there is no unit present in it in actuality; for actuality is the cause of the separate existence of each substance and it is the factor which separates substances from each other. ${ }^{100}$

It is worthwhile mentioning that Radke, taking into consideration the constitution of mathematical number proposed by Syrianus, draws a distinction between the mathematical number and the monadic number and identifies the latter only with the matter of the mathematical number. Furthermore, within this line of interpretation the monadic number is associated with the multiplicity, while the mathematical number with the unity. ${ }^{101}$ This interpretation seems to contribute to the reinforcement of the platonic conception of mathematical number adopted by Syrianus, while also conforming to Syrianus's tendency towards a combination of basic Platonic and Aristotelian doctrines, since Radke does not abandon the Aristotelian hylomorphic approach but exploits it in order to amplify its usefulness to the explanation of Syrianus's understanding of the mathematical number. This is obvious when Radke also asserts that the form is the constituent which distinguishes each specific mathematical number from the others, while its matter is the component which characterizes its being in general a number. ${ }^{102}$

\footnotetext{
96 See Arist. Phys. 184 a 10-16.

97 Syrian. 152, 2-5.

98 Syrian. 152, 5-10.

99 Translation Bostock (1994).

${ }^{100}$ On this matter see also Ps.-Alex. In Metaph. 525, 40-526, 27; Asclep. In Metaph. 432, 8-27.

101 Radke (2003: 523).

102 Radke (2003: 518).
} 
Syrianus prompts us to take due note of this, that Aristotle is neither willing to accept that number is a system of units, ${ }^{103}$ nor acknowledges that units are anything at all in actuality, until they are brought to order by Forms. ${ }^{104}$ Mueller argues that according to Syrianus, the Euclidean multiplicities are not real numbers ${ }^{105}$. Furthermore, he notes that Syrianus, "has abandoned the Euclidean conception of numbers as arbitrary multiplicities of monads for a conception in which mathematical numbers are forms possessed by such multiplicities, forms which are generated sequentially from an originative monad". ${ }^{106}$ This last thesis, according to Mueller, proves that here Syrianus clearly has the neo-Pythagorean conception of number in mind. ${ }^{107}$

I agree with Mueller that in Syrianus's conception of number we can partly trace a neo-Pythagorean influence, at least in terms of the sequential generation of forms of numbers from an originative monad. But on the other hand he seems to praise Aristotle for rejecting the view expressed by Theon of Smyrna, that number is a system of monads. I also agree that Syrianus abandons the Euclidean multiplicities of monads or units, on the grounds that they are not real numbers, because it is easy for them to become numbered things, i.e. countables (arithmèta), instead of being numbers. ${ }^{108}$ Mueller is correct when he recognizes as one kind of motivation for this abandonment of the Euclidean conception of number, the thesis that a multiplicity of monads by itself is only a heap (sōros) and not a unified thing. ${ }^{109}$ Another reason for the abandonment of the idea that numbers are collections of monads or units, is the assumption that since monads are undifferentiated, one can easily reach the conclusion that there is only one monad, the monad itself. Consequently, the difference between number seven and number five is not quantitative but formal. Seven is not more than five because it contains more monads than five; seven and five are just different forms. ${ }^{110}$

Mueller takes into consideration Proclus's approach, according to which the monad, unlike the point, is without position, since it is immaterial and outside all extension and

103 This reference of Syrianus reminds us of the definition of number offered by Theon of Smyrna: "A number is a system of monads or a progression of multiplicity which proceeds from the monad and a retrogression ending in the monad" (Mathematics Useful for Understanding Plato, 18, 3-5); cf. Nicom. Introduction to Arithmetic, I 7, 1-2; this definition is also ascribed to the neo-Pythagorean Moderatus of Gades; see Stob. Anth. I 8, 1-11. Mueller (2000: 75) takes the first part of the above mentioned definition to be equivalent to Euclid's: "A number is a multitude composed of units" (Euclid's Elements VII, Def. 2); he also thinks, as Dodds does, that the second part of this definition, which labels neo-Pythagorean, is closely related to proposition 21 of Proclus's Elements of Theology.

\footnotetext{
104 Syrian. 152, 8-10.

105 Mueller (2000: 79).

106 Mueller (2000: 81).

107 Mueller (2000: 80). number of numbered things.

109 Mueller (2000: 81).
110 Mueller (2000: 81).
}

108 See Syrian. 132, 33-34; 135, 28-32; 136, 15-17; Syrianus distinguishes between monadic number and the 
place. ${ }^{111}$ Based on this assumption, he suggests that monads cannot be differentiated because of their lack of position. ${ }^{112}$ In my view, this is not a sufficient justification of the fact that the units of mathematical number cannot be differentiated, because the eidetic numbers are differentiated although they also lack position. According to Aristotle, ${ }^{113}$ the eidetic numbers exhibit serial order, and they have an ordering relation based on priority and posteriority; but we can understand that this priority and posteriority is neither temporal nor local, because Forms are dissociated from time and place. Mathematical numbers, unlike eidetic numbers, do not exhibit serial order. Mueller explains this difference as follows: "since there is one ideal two, three, and four, the ideal three has a unique predecessor and successor whereas an arithmetic three does not since there are infinitely many arithmetic twos and fours". ${ }^{114}$ In my opinion this is a reasonable explanation.

Many years before Mueller, Wilson and Cherniss offered another plausible explana-

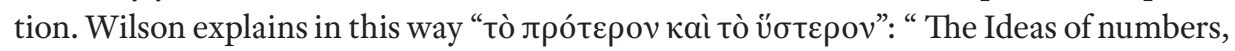
as being the Universals of number and therefore $\dot{\alpha} \sigma \dot{v} \mu \beta \lambda \eta \tau o \iota$, are as $\dot{\alpha} \sigma \dot{v} \mu \beta \lambda \eta \tau o \iota$ entirely outside one another, in the sense that none is a part of another. Thus they form a series of different terms, which have a definite order...". ${ }^{115}$ Cherniss suggests that Aristotle's own scattered remarks make it possible to see how Plato conceived the differentiation of these quantitatively indifferent numbers. He explains that, "because they are inaddible and so entirely outside of one another in the sense that none is part of any other, these ideal numbers stand to one another in the relation of prior and posterior; and this relation is the serial order, two-three-four and so forth...What distinguishes each of the ideal numbers from all the rest is its position in this series...” ${ }^{116}$ What we must carefully note here is that the "position in this series" is a matter of order rather than a matter of real position in place. Cherniss correctly stresses that this order is not one of ontological priority. ${ }^{117}$ This assumption is connected with Aristotle's testimony that the Platonists

111 Procl. In Eucl. 95, 23-96, 11.

112 Mueller (2000: 81).

113 See again Arist. Metaph. 1080 a 17-18.

114 Mueller (1986: 114). Cf. Burnyeat (1987: 237, n. 61). Mueller correctly stresses that Aristotle uses the idea of priority and posteriority to contrast one kind of congeries of units, idea numbers or eidetic numbers, with another, intermediate, i.e. mathematical, number.

115 Wilson (1904: 253). Wilson (1904: 253-254) clarifies that the mutual exclusiveness of the eidetic numbers, caused by their being $\alpha \dot{\alpha} \mu \beta \beta \lambda \eta \tau o \iota$ (incomparable), enables them to form an ordered series or a serial order, whereas the inclusiveness of one number in another in the mathematical number prevents it from having the prior and posterior; see 1080 a $30-33$.

116 Cherniss (1962: 35).

117 Cherniss (1962: 36). Klein (1992: 89-93) construes in a different way this taxis (order) of eidetic numbers. According to Klein, the very formulation of the possibility of the koinōnia tōn eidōn (or of genōn) indicates the arithmos structure of the genē; within this framework the eide form assemblages of monads, i.e., arithmoi of a peculiar kind. The assemblages of eidē, the arithmoi eidetikoi, cannot enter into any "community" with one another; their monads are all of different kind and can be brought together only partially, namely only insofar they belong to one and the same assemblage. Klein explains that the notion of an "arithmetic" structure of the realm of ideas permits a solution of the ontological methexis problem. The arithmoi eidetikoi, according to him, 
did not posit a general idea of number, precisely because numbers stand to one another as prior to posterior. ${ }^{118}$

In my view, the main motivation behind Syrianus's treatment of mathematical number was to display the existence of two different natures within this number, one formless and the other formal, and to set out the conception of the formal and efficient cause of mathematical number. ${ }^{119}$ The proximate efficient cause of mathematical number is the substantial mathematical number by which the Demiurge has structured our rational soul and which by its innate power generates the unitary number. And since the substantial mathematical number exists within our soul it is totally clear that it is distinct from the eidetic number. Although it is also called "eidetic number", it must not be confused with the real eidetic number. But the properly said efficient cause of the mathematical number is the arithmetic soul, which by possessing within itself the originative monad imposes form upon all numbers and in this way generates all numbers.

Arithmetic soul produces mathematical numbers from two principles that it possesses within itself, and from which the whole of the mathematical number is born, the monad and the dyad. It is worthwhile to consider what the relationship is between the substantial mathematical number and the two principles. Since the substantial mathematical number has been given to the rational soul by the Demiurge, it is prior to the unitary number, but it must also be prior to these two principles which exist within our souls, or at least comprehensive in relation to them, for two reasons. Firstly, the soul possesses within itself these two principles, whereas the substantial mathematical number has been given to the soul from without by the Demiurge, and only to the rational soul. Moreover, the substantial mathematical number seems to represent the mathematical structure and the well-ordered constitution of the soul; part of this structure and constitution are

are intended to make intelligible the inner articulation of the realm of ideas; they define each eidos ontologically as a being which has multiple relations to other eidè in accordance with their particular nature and which is nevertheless in itself altogether indivisible. Klein points out that for Plato the "numerical" being of the noèta means their ordered being, their taxis; this taxis of eidetic numbers is logically expressed in the relation of "being superior" or "inferior" in the order of eidē; the higher the genos, i.e., the less articulated the eidetic number, the more original and comprehensive it is. So Klein traces a superiority and inferiority within this taxis of eide, because he understands this taxis within the frame of the koinonia tôn eidōn; the monads which constitute an eidetic number, i.e., an assemblage of ideas, are nothing but a conjunction of eide which belong together to one and the same eidos of a higher order, namely to a "class", a genos.

118 See Arist. NE 1096 a 17-19; cf. Arist. Metaph. 999 a 6-9. For the dissolution of a misunderstanding of the first passage see Wilson (1904: 247-248). Wilson clarifies its meaning saying that the Platonists held that the Ideal numbers had no one Idea of number corresponding to them as a group; i.e, there was no "Idea" corresponding to number in general. Klein (1992: 93) explains that every eidetic number is either "superior" or "inferior" in this order with respect to its neighbor, so that a subsumption of all these numbers under one idea common to all, namely " number in general", is quite impossible. Cherniss (1962: 36) states that Aristotle himself generalized this principle referred to in the passage of $N E$, and used it to refute the existence of ideas which Plato certainly posited. Cherniss asserts that "as soon as the essence of each idea of number is seen to be just its unique position as a term in this ordered series, it is obvious that the essence of number in general can be nothing but this very order, the whole series of these unique positions". His conclusion is that the idea of number in general, then, is the series of ideal numbers itself. He further points out that to posit an idea of number apart from this would be merely to duplicate the series of ideal numbers.

119 I think the most important passage which strongly supports this interpretation is Syrian. 133, 17-26. 
obviously these two principles. Secondly, these two principles, the monad and the dyad, from which we generate mathematical numbers, are not original principles but are in fact images of the first principles and pre-contain all of the formal features of mathematical numbers; ${ }^{120}$ the first is only analogous to the Monad in the intelligible realm, while the second is an image of the Indefinite Dyad which is intelligible.

There is one final extremely important question regarding the ontological status of the mathematical number. Radke claims that since mathematical numbers admit mathematical operations and these operations always and necessarily concern the particulars, we can reach the conclusion that whereas the eidetic number is something universal, ${ }^{121}$ the mathematical number is a kind of particular. ${ }^{122}$ I do not agree with the idea that the eidetic numbers are simply universals, because the platonic Forms are not simply universals; nor do I agree with the view that the mathematical number is a kind of particular. We have seen that Syrianus $(135,32-136,11)$ supports the view that any given mathematical number is just one, for it is a universal, and also that there is only one single Form of the totality of mathematical number. From Syrianus's words we can assume that the totality of mathematical number (the mathematical numbers as a whole) is one single Form, although composed of all the mathematical numbers, each being considered as a unique universal. If the mathematical numbers were infinitely many, then the science of mathematics could not exist. ${ }^{123}$

In my view, the totality of mathematical number needs to be conceived as a universal in the sense of comprehensive and unique, since there is only one such series, consisting of universals each of which is unique. ${ }^{124}$ Each particular mathematical number is a universal in the sense of unique, unrepeatable or unreproducible, and prior. If we multiply and repeat many times the form, i.e. this constituent which defines and gives existence to the mathematical numbers, then we would be compelled to convert them from numbers into countables. On the grounds of this assumption one could definitely attribute to the mathematical numbers the status of a separate existence. Given that the status of separate existence is primarily acknowledged to the eidetic numbers, ${ }^{125}$ there remains only one

120 O’Meara (1989: 133).

121 Radke (2003: 524). According to Radke, the eidetic number is also composite, but its matter, which is genuinely appropriate to its form, has also the status of universal.

122 Radke (2003: 523, 528).

123 Syrian. 136, 6-8; see also Radke (2003: 526).

124 Cf. Wilson (1904: 253).

125 The Phaedo (96 e-101 d) attests that a separate idea of each number is posited by Plato and that participation is the way in which the multiplicities of numbers are related to each ideal-number. Ideal-numbers are not combinations or congeries of units, but each idea is a perfect unity, a simple and unique unity which is irreducibly itself and nothing else, just as is every other idea; see Cherniss (1962: 34) and Tarán (1981: 14). The latter (1978: 83 ; 1981: 15-16) claims that ideal numbers are the hypostatization of the series of natural numbers. Cherniss (1962: 34) suggests that "once it is recognized, however, that the ideas of numbers are not aggregates of units at all but are the universals of number, each of which is a perfect and unique unit without parts, the phenomenal numbers which are aggregates can be related to them as images or imitations". Nevertheless, Cherniss stresses the difficulties which are involved in the idea that particular numbers fall short of their models and invokes passage 
solution to the question of the difference between these two kinds of number. While eidetic numbers are not constituted of units, the mathematical numbers are monadic or unitary, i.e. they have a quantitative or material substratum which represents their monadic or unitary aspect; but what defines and determines their being is their form, which has the status of a Platonic Form. This means that according to Syrianus's view, we can construe mathematical number as a synthesis of the eidetic and the monadic or unitary number. Its eidetic aspect betrays an entirely Platonic approach, whereas its monadic or unitary aspect reveals the Aristotelian hylomorphic conception of it. Consequently, we can recognize in Syrianus's interpretive analysis of the mathematical number, a complete synthesis of the Platonic and Aristotelian Ontology. We can also assume that he receives and transmits the Platonic tradition, while in parallel inserting in it fundamental innovations of Aristotelian origin.

As it concerns the epistemological status of mathematical knowledge, I believe that Mueller ${ }^{126}$ is correct that in passage $133,10-15$ Syrianus presents arithmetical knowledge as something which exists a priori in our souls, since it is innate and inherent in the very structure of the soul. I also believe the same is true for passage 123, 19-23 of Syrianus's Commentary. According to him, the science of arithmetic inheres in us by nature, so it belongs to the souls of all people, and has dianoetic matter, so that it can give form to the matter easily and timelessly. This thesis verifies that mathematics is not invented but a priori (in the sense that it has been given to our souls), universal and necessary; ${ }^{127}$ and with this status it can henceforth play a considerably creative role in the production of our knowledge.

$432 \mathrm{a}-\mathrm{b}$ of the Cratylus in order to highlight this problem. Wilson (1904: 253) also states that the Ideas of numbers are the Universals of number. Mueller (1986: 112-113) admits that "Plato may have well thought that numerical universals were numbers" but raises the question as to what the relationship between these numerical forms or ideas and real (i.e. "natural") numbers is. In any case Mueller (2000: 82) is correct when he points out that the above mentioned passage of the Phaedo seems to have played the most significant role in Syrianus's treatment of number. I agree that this passage seems to have significantly affected all of the Platonists, since it is the most important evidence of the platonic thesis on the separate existence of numbers.

126 Mueller (2000: 78). The two principles of mathematical numbers also exist in our souls, according to Syrianus, and play a role not only in number psychology, epistemology and the explanation of our number judgements, as Mueller (2000: 77) correctly stresses, but more generally in the way the soul conceives of a wide range of phenomena and noèta (intelligibles) associated with numbers.

127 O’Meara (1989: 134). 


\section{BIBLIOGRAPHY}

\section{Primary sources}

AleXAnder Aphrodisias, In Aristotelis Metaphysica commentaria, M. Hayduck (ed.), Berolini 1891 (CAG I). AsclePIUs, In Aristotelis Metaphysicorum libros A-Z commentaria, M. Hayduck (ed.), Berolini 1888 (CAG VI 2). EuCLIDEs Elementa, E.S. Stamatis (ed.), Leipzig 1969-1977.

EuCLIDES, The thirteen books of Euclid's Elements, T.L. Heath (transl.), New York 1956.

Nicomachus Gerasenus, Introductionis arithmeticae libri II, R.G. Hoche (rec.), Leipzig 1866.

Proclus, The Elements of Theology, by E.R. Dodds (transl., introd. \& comm.), Oxford $1963^{2}$.

Proclus, In primum Euclidis Elementorum librum Commentarii, G. Friedlein (ed.), Leipzig 1873.

Proclus, A commentary on the first book of Euclid's Elements, G.R. Morrow (transl., introd. \& notes), Princeton 1970 .

IoAnnes Stobaeus, Anthologium, C. Wachsmuth, O. Hense (rec.), Berlin 1958.

Syrianus, In Metaphysica commentaria, G. Kroll (ed.), Berlin 1902 (CAG VI 1).

Theon SMyrnaeus, Expositio rerum mathematicarum ad legendum Platonem utilium, E. Hiller (rec.), Leipzig 1878. Theon of Smyrna, Mathematics Useful for Understanding Plato, C. Toulis et al. (transl.), San Diego 1979.

\section{Secondary works}

AnNas, J., 1976 (reprinted 1999), Aristotle's Metaphysics, Books M and N, Translated with Introduction and Notes, Oxford.

Bostock, D., 1994, Aristotle, Metaphysics, Books $Z$ and H, Translated with a Commentary, Oxford.

Burnyeat, M.F., 1987, Platonism and Mathematics: A Prelude to Discussion, in: A. Graeser (ed.), Mathematics and Metaphysics in Aristotle = Mathematik und Metaphysik bei Aristoteles, Sigriswil, 6.-12. September 1984, Bern and Stuttgart, pp. 213-240.

Cherniss, H., 1944, Aristotle's Criticism of Plato and the Academy, Vol. I, Baltimore.

Cherniss, H., 1962, The Riddle of the Academy, New York.

Dillon, J., O’Meara, D., 2006, Syrianus, On Aristotle's Metaphysics 13-14, Ithaca, New York.

Dooley, W.E., 1989, Alexander of Aphrodisias: On Aristotle's Metaphysics 1, Ithaca.

KLEIN, J., 1992, Greek Mathematical Thought and the Origin of Algebra, E. Brann (transl.), New York.

LERNould, A., 2009, “Les réponses du platonicien Syrianus aux critiques faites par Aristote en Métaphysique $M$ et $N$ contre la thèse de l' existence séparée des nombres”, in: A. Longo (ed.), Syrianus et la Métaphysique de l'Antiquité tardive, Bibliopolis, pp. 133-159.

Mouzala, M.G., 2008, Ousia kai Orismos, Hē Problēmatikē tēs henotētos eis ta oikeia kephalaia tōn "Meta ta Physika" tou Aristotelous (Substance and Definition: The Problematic of Unity in the relevant chapters of Aristotle's Metaphysics), Athens.

Mueller, I., 1986, “On some Academic Theories of Mathematical Objects”, Journal of Hellenic Studies 106, pp. $111-120$.

Mueller, I., 2000, “Syrianus and the Concept of Mathematical Number”, in: G. Bechtle, D. J. O’Meara (eds.), La philosophie des mathématiques de l' Antiquité tardive, Fribourg, pp. 71-83. 
Mueller-Jourdan, P., 2009, “L’ indéterminé 'matière' chez Syrianus. Brève exégèse d' In Metaphysica 133, 15-29”, in: A. Longo (ed.), Syrianus et la Métaphysique de l’Antiquité tardive, Bibliopolis, pp. 161-173. O’ MeArA, D.J., 1989, Pythagoras Revived, Mathematics and Philosophy in Late Antiquity, Oxford.

RADKe, G., 2003, Die Theorie der Zahl im Platonismus, Ein systematisches Lehrbuch, Tübingen.

Ross, W.D., 1924, Aristotle's Metaphysics, A revised text with Introduction and Commentary, Vols. I-II, Oxford.

ShePparD, A.D.R., 1982, "Monad and Dyad as Cosmic principles in Syrianus", in: H.J. Blumenthal, A.C. Lloyd (eds.), Soul and the Structure of Being in Late Neoplatonism, Syrianus, Proclus, and Simplicius, Papers and discussions of a colloquium held at Liverpool, 15-16 April 1982, Liverpool, pp. 1-14.

TARÁn, L., 1978, “Aristotle’s Classification of Number in Metaphysics M 6, 1080 a 15-37”, Greek, Roman and Byzantine Studies 19, pp. 83-90.

TARÁn, L., 1981, Speusippus of Athens, A Critical Study With a Collection of the Related Texts and Commentary, Leiden: Brill.

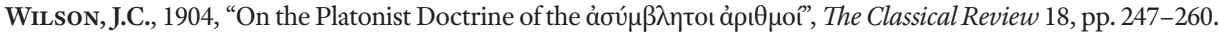

MELINA MOUZALA

/University of Patras /

KEYWORDS

\section{Syrianus on the Platonic Tradition of the Separate Existence of Numbers}

This paper analyzes and explains certain parts of Syrianus's Commentary on book M of Aristotle's Metaphysics, which details Syrianus's response to Aristotle's attack against the Platonic position of the separate existence of numbers. Syrianus defends the separate existence not only of eidetic but also of mathematical numbers, following a line of argumentation which involves a hylomorphic approach to the latter. He proceeds with an analysis of the mathematical number into matter and form, but his interpretation entails that form is the constituent of number, which has the status and role of a Platonic Form. This solution allows him not only to explain and justify the unity of number, but also to apply the Platonic thesis of the separate existence of numbers, to the mathematical or monadic numbers themselves. It also betrays its tendency to combine theses of the Platonic Ontology with fundamental Aristotelian doctrines.

Syrianus, Neoplatonism, Plato, Aristotle, eidetic number, mathematical number, monadic number 